\title{
Smoking during pregnancy and diabetes mellitus in a British longitudinal birth cohort
}

\author{
Scott M Montgomery, Anders Ekbom
}

Enheten för Klinisk Epidemiologi, Karolinska Sjukhuset L1:00 SE-171 76,

Stockholm, Sweden

Scott M

Montgomery

principal research

fellow

Anders Ekbom

professor

Correspondence to:

Dr Montgomery

Scott.

Montgomery@

medks.ki.se

BMJ 2002;324:26-7
Exposures in utero may increase the risk of type 2 diabetes. ${ }^{12}$ We tested the hypothesis that maternal smoking during pregnancy increases both the risk of early onset type 2 diabetes $^{3}$ and non-diabetic obesity in offspring.

\section{Methods and results}

We used data are from the British National Child Development Study (NCDS), ${ }^{4}$ based on the Perinatal Mortality Survey (PMS) of about 17000 births from 3 to 9 March 1958. The first sweep of the study in 1965 had 15396 responses. The cohort remained generally representative at age 33 years $(n=11359) .^{5}$ Missing data reduced the proportion in social class $\mathrm{V}$ from $6.4 \%$ in sweep 1 to $5.3 \%$. Ethics committee approval was obtained for research involving medical examinations, and cohort members signed consent forms at age 33 years allowing access to medical records.

Medical examinations and record reviews by local authority medical officers were conducted at ages 7 and 16 years. Children with incomplete or equivocal information on diabetes or with a recorded onset before the age of 16 were not included in the main analysis as they are unlikely to have type 2 diabetes. A personal interview at age 33 years asked about diabetes. Those with only gestational diabetes were also excluded: 15 men and 13 women with an onset of diabetes between 16 and 33 years were identified.

At birth midwives recorded information on the child's sex, birth weight, mother's age, her age on leaving full time education, family social class, and smoking during pregnancy (after the 4th month) divided into non-smokers, medium (1-9 cigarettes/day) heavy $(>10)$, and variable (a balance of medium and heavy). Details of maternal smoking were again recorded in
1974 , as non-smoking and $<1,1-5,6-10,11-20,21-30$, or $>30$ cigarettes/day.

Cohort members' own smoking behaviour was recorded during an interview at age 16 and they were classified as non-smokers or as smoking $<1$, 1-9, $10-19, \quad 20-29,>29$ cigarettes/week. Interviewers measured height in centimetres and weight in kilograms using stadiometers and electronic balances at age 33. Multiple logistic regression analysis was used for two outcomes: diabetes and body mass index (BMI) of over 30 , independent of diabetes. Where obesity was the outcome, those with diabetes were excluded and we adjusted for sex, own smoking at age 16, and all the maternal factors at birth.

Some $10 \%(n=602)$ were obese $(\mathrm{BMI}>30)$ at age 33. After we excluded the diabetic cohort members the adjusted odds ratios (and 95\% confidence intervals) for obesity associated with maternal smoking during pregnancy are 1.34 (1.07 to 1.69 ), 1.35 (0.95 to 1.92$)$, and 1.38 (1.06 to 1.79 ), with a statistically significant trend $(\mathrm{P}=0.003)$ for medium, variable, and heavy smokers, respectively (table). Non-diabetic cohort members who smoked at age 16 did not have an increased risk of obesity.

\section{Comment}

The association of diabetes with maternal smoking during pregnancy (independent of finer-grain measures of mothers' smoking in 1974, own smoking at age 16 , and other potential confounding factors) suggests that it is a true risk factor for early adult onset diabetes. Cigarette smoking as a young adult was also independently associated with an increased risk of subsequent diabetes.

Maternal smoking in pregnancy, own smoking at age 16 years, and risk of diabetes among young adults. Odds ratio with $95 \%$ confidence intervals using logistic regression with a diagnosis of diabetes after age 16 as the dependent variable

\begin{tabular}{|c|c|c|c|c|c|c|c|}
\hline \multirow{2}{*}{$\begin{array}{c}\text { People } \\
\text { without } \\
\text { diabetes } \\
\text { No (\%) }\end{array}$} & \multirow{2}{*}{$\begin{array}{l}\text { People with } \\
\text { diabetes } \\
\text { No (\%) }\end{array}$} & \multicolumn{2}{|c|}{ Unadjusted } & \multicolumn{2}{|c|}{ Adjusted ${ }^{*}$} & \multicolumn{2}{|c|}{ Adjusted $\dagger$} \\
\hline & & OR $(95 \% \mathrm{Cl})$ & $P$ & OR $(95 \% \mathrm{Cl})$ & $\mathbf{P}$ & OR (95\% Cl) & $P$ \\
\hline
\end{tabular}

\begin{tabular}{|c|c|c|c|c|c|c|c|c|}
\hline \multicolumn{9}{|c|}{ Mother smoking while pregnant (after 4th month) } \\
\hline Non-smoker & $3430(69.8)$ & $12(42.9)$ & 1.00 & & 1.00 & & 1.00 & \\
\hline Medium smoker & $689(14.0)$ & $3(10.7)$ & 1.24 (0.35 to 4.42$)$ & 0.735 & 1.11 (0.31 to 4.04$)$ & 0.872 & 1.01 (0.23 to 4.53$)$ & 0.990 \\
\hline $\begin{array}{l}\text { Varies between } \\
\text { medium and heavy }\end{array}$ & $277(5.6)$ & $4(14.3)$ & $4.13(1.32$ to 12.88$)$ & 0.015 & $4.13(1.27$ to 13.40$)$ & 0.018 & 3.55 (0.88 to 14.38$)$ & 0.076 \\
\hline Heavy smoker & $521(10.6)$ & $9(32.1)$ & $4.94(2.07$ to 11.77$)$ & $<0.001$ & $4.55(1.82$ to 11.36$)$ & 0.001 & $4.02(1.14$ to 14.14$)$ & 0.030 \\
\hline \multicolumn{9}{|c|}{ 0wn smoking at age 16 years (cigarettes/week) } \\
\hline Non-smoker & $3251(66.1)$ & $13(46.4)$ & 1.00 & & 1.00 & & 1.00 & \\
\hline$<1$ & $147(3.0)$ & $1(3.6)$ & $1.70(0.22$ to 13.09$)$ & 0.610 & $2.09(0.254$ to 17.23$)$ & 0.492 & $2.07(0.25$ to 17.19$)$ & 0.502 \\
\hline $1-9$ & $510(10.4)$ & $3(10.7)$ & $1.47(0.42$ to 5.18$)$ & 0.548 & $1.76(0.48$ to 6.46$)$ & 0.394 & $1.92(0.52$ to 7.10$)$ & 0.332 \\
\hline 10-19 & $176(3.6)$ & $2(7.1)$ & 2.84 (0.64 to 12.69$)$ & 0.171 & $2.41(0.51$ to 11.41$)$ & 0.268 & 2.48 (0.52 to 11.97$)$ & 0.257 \\
\hline $20-29$ & $189(3.8)$ & $1(3.6)$ & 1.32 (0.17 to 10.17$)$ & 0.788 & $1.42(0.177$ to 11.43$)$ & 0.741 & $1.61(0.20$ to 12.96$)$ & 0.653 \\
\hline $30_{+}$ & $644(13.1)$ & $8(28.6)$ & 3.11 (1.28 to 7.52$)$ & 0.012 & $3.53(1.40$ to 8.91$)$ & 0.008 & 3.62 (1.42 to 9.24$)$ & 0.007 \\
\hline
\end{tabular}

*Adjusted for maternal smoking during pregnancy, sex, mother's age at birth of cohort member, age mother left school, family social class at birth, birth weight, own smoking at age 16 years, and BMI at age 33 years.

†Adjusted for all of the above and maternal smoking in 1974. 
In utero exposures due to smoking during pregnancy may increase the risk of both diabetes and obesity through programming, resulting in lifelong metabolic dysregulation, possibly due to fetal malnutrition or toxicity. The odds ratios for obesity without type 2 diabetes are more modest than those for diabetes and the scope for confounding may be greater. Smoking during pregnancy may represent another important determinant of metabolic dysregulation and type 2 diabetes in offspring. Smoking during pregnancy should always be strongly discouraged.

We thank the Centre for Longitudinal Studies, Institute of Education, London University, who supplied these data.

Contributors: Both authors wrote this paper and will act as guarantors. SMM conducted the analysis.
Funding: None.

Competing interests None.

1 Barker DJ, Hales CN, Fall CH, Phipps K, Clark PM. Type 2 (non-insulindependent) diabetes mellitus, hypertension and hyperlipidaemia (syndrome $\mathrm{X}$ ): relation to reduced foetal growth. Diabetologia 1993;36:62-7.

2 Valdez R, Athens MA, Thompson GH, Bradshw BS, Stern MP. Birth-weight and adult health outcomes in a biethnic population in the USA. Diabetologia 1994:37:624-31.

3 Orahilly S, Spivey RS, Holman RR, Nugent Z, Clark A, Turner RC. Type-II diabetes of early onset-a distinct clinical and genetic syndrome $B M J$ 1987;294:923-8.

4 Ekinsmyth C, Bynner JM, Montgomery SM, Shepherd P. An Integrated approach to the design and analysis of the 1970 British Cohort Study (BCS70) and the National Child Development Study (NCDS). London: Centre for Longitudinal Studies, University of London, 1992.

5 Ferri E. Life at 33: the fifth follow-up of the National Child Development Study. London: National Children's Bureau, 1993.

\section{Drug points}

\section{Ticlopidine associated with acute arthritis}

Habib A Dakik, Ibrahim Salti, Rachid Haidar, Imad W Uthman, American University of Beirut Medical Center, Beirut, Lebanon

Ticlopidine is an antiplatelet thienopyridine drug that works by non-competitive antagonism of the ADP receptor. It is used widely to prevent thrombosis after coronary stent placement and has been shown to be at least as effective as aspirin in preventing events in patients with cerebrovascular disease. ${ }^{12}$ Its most common side effects include diarrhoea, nausea, vomiting, and skin rash. ${ }^{3}$ It also has serious-but rare-side effects such as neutropenia, thrombotic thrombocytopenic purpura, and bone marrow aplasia. ${ }^{3}$ We report a case of acute arthritis associated with ticlopidine.

A 65 year old woman was admitted to hospital because of chest pain. She was known to be taking insulin for diabetes and had developed non- $Q$ wave myocardial infarction. She was also hyperlipidaemic. Cardiac catheterisation showed two vessel coronary artery disease, for which she had successful angioplasty with stent placement. She was discharged home after taking ticlopidine $250 \mathrm{mg}$ twice daily for five days in addition to her previous drugs (aspirin, pravastatin, and insulin).

She started to develop a diffuse rash one week after discharge and had pain and swelling in the joints of her hands, wrists, and knees. No fever, chills, or malaise was reported. She had no history of allergies or drug adverse reactions. On physical examination she was afebrile and had erythematous urticarial lesions over the trunk and extremities. Examination of her joints showed erythema, hotness, swelling, and tenderness in all the proximal interphalangeal and metacarpophalangeal joints, the wrists, and knees. Her blood tests at that time showed a packed cell volume of 0.34 , a white blood cell count of 9700 cells/ $\mathrm{mm}^{3}$, and a platelet count of 211000 cells $/ \mathrm{mm}^{3}$. Her erythrocyte sedimentation rate was $97 \mathrm{~mm} / \mathrm{h}$ and her serum uric acid concentration was $250 \mu \mathrm{mol} / \mathrm{l}$. Her test results were negative for hepatitis $\mathrm{B}$ surface antigen, hepatitis $\mathrm{C}$ antibodies, IgM and IgG parvovirus antibodies, antinuclear antibodies, and rheumatoid factor. Chest radiography was normal and analysis of her urine showed no haematuria or proteinuria.
The presumptive diagnosis was a symmetrical polyarthritis associated with ticlopidine intake. Treatment with ticlopidine was discontinued, and one week later her rash resolved completely but her arthritis persisted. After treatment with a non-steroidal anti-inflammatory drug (diclofenac $75 \mathrm{mg}$ intramuscularly twice daily) for 10 days, her arthritis gradually resolved. Two weeks later her joints were completely normal and her erythrocyte sedimentation rate decreased to $32 \mathrm{~mm} / \mathrm{h}$. On her last evaluation, six months after the onset of arthritis, she had had no recurrence of her joint pain, and her erythrocyte sedimentation rate had dropped to $18 \mathrm{~mm} / \mathrm{h}$.

The clinical features and laboratory findings of arthritis in this case suggest a drug induced hypersensitivity (leucocytoclastic) vasculitis. Before March 2001, one case of polyarthritis and three cases of arthralgia associated with ticlopidine had been reported to the Committee on Safety of Medicines in the United Kingdom. Two case reports of arthritis associated with clopidogrel have also been published. ${ }^{4}$ Clopidogrel is a thienopyridine drug with a similar chemical structure to ticlopidine and is commonly used in patients undergoing coronary stent implantation. Sanofi-Synthelabo, the manufacturer of ticlopidine, has not reported any case of polyarthritis associated with taking the drug. We suggest that thienopyridine derivatives be considered as a potential cause of acute arthritis.

Funding: None.

Competing interests: None declared.

1 Leon MB, Baim DS, Popma JJ, Gordon PC, Cutlip DE, Ho KK, et al. A clinical trial comparing three antithrombotic-drug regimens after coronary artery stenting. $N$ Engl J Med 1998;339:1665-71.

2 Hass WK, Easton JD, Adams HP Jr, Pryse-Phillips W, Molony BA, Anderson S, Kamm B. A randomized trial comparing ticlopidine hydrochloride with aspirin for the prevention of stroke in high-risk patients. Ticlopidine Aspirin Stroke Study Group. N Engl J Med 1989;321:501-7.

3 Quinn MJ, Fitzgerald DJ. Ticlopidine and clopidogrel. Circulation 1999;100:1667-72.

4 Garg A, Radvan J, Hopkinson N. Clopidogrel associated with acute arthritis. BMJ 2000;320:483. 